\title{
Recovery from lateralized neocortical damage: dissociation between amphetamine-induced asymmetry in behavior and striatal dopamine neurotransmission in vivo
}

\author{
Edward Castañeda $^{1}$, Ian Q. Whishaw ${ }^{1}$ and Terry E. Robinson ${ }^{1,2}$ \\ ${ }^{I}$ Department of Psychology, University of Lethbridge, Lethbridge, Alta (Canada) and ${ }^{2}$ Department of Psychology, University of Michigan, \\ Ann Arbor, MI 48109 (U.S.A.)
}

(Accepted 17 September 1991)

Key words: Hemidecortication; Dialysis; Dopamine release; Amphetamine; Dihydroxyphenylacetic acid; Homovanillic acid; 5-Hydroxyindoleacetic acid; Locomotion

\begin{abstract}
It has been hypothesized that neocortical damage is accompanied by secondary changes in other brain areas (the shock or diaschisis of von Monakow), which contributes to initial non-specific behavioral depression. The relation between behavioral changes and dopamine (DA), serotonin (5-HT), and their metabolites, measured with intracerebral microdialysis in freely moving rats and by tissue assay postmortem, was examined during postsurgical recovery from unilateral hemidecortications. Rats were tested for rotational asymmetry and extracellular concentration of DA was measured both during rest and after amphetamine $(1.5 \mathrm{mg} / \mathrm{kg})$. It was found that: (1) during the first few postsurgical days the hemidecorticate rats rotated ipsilateral to their lesions after amphetamine but thereafter on tests given up to 121 days postsurgery there was no asymmetry in rotation; (2) there were no asymmetries in the concentration of DA or its metabolites at any time after surgery; (3) the 5-HT metabolite 5-hydroxyindoleacetic acid (5-HIAA) was elevated acutely for a few days following surgery; (4) during the first 3 postoperative days, both baseline extracellular 3,4-dihydroxyphenylacetic acid (DOPAC) and amphetamine-induced DA release were significantly elevated bilaterally. These findings demonstrate that the acute behavioral asymmetry in rotation produced by hemidecortication is not related to unilateral changes in striatal DA activity and its metabolites. Thus, the behavioral asymmetries might be related to other striatal changes (i.e. 5-HIAA) or other damage, such as to the corticospinal projections of the lesioned hemisphere. Nevertheless, unilateral lesions did produce acute bilateral increases in DA levels, which may be a correlate of generalized neural shock produced by the lesion.
\end{abstract}

\section{INTRODUCTION}

Damage to the neocortex produces many complex changes in behavior. Some behavioral deficits appear to be relatively permanent and, therefore, such functions presumably require the integrity of the tissue that was damaged. Other behavioral deficits produced by neocortical damage are only transient; that is, the initial impairments are followed by recovery of function. As early as 1911 von Monakow suggested that this secondary category of change was produced by diaschisis (or shock) involving some other area of the brain that is functionally related to, but distant from, the site of injury ${ }^{26}$. The present study was designed to examine whether some of the acute and chronic changes in behavior seen following damage to the neocortex may be related to changes in striatal function, as has been suggested previously ${ }^{2,16}$. 32

There are a number of reasons why neocortical dam- age may alter striatal function, and thus contribute to the pattern of behavioral deficits seen following a neocortical lesion. First, neocortical injury in rats produces a number of shock-like behavioral changes that dissipate over recovery periods lasting as long as one year ${ }^{41}$. Second, anatomical evidence indicates that there is a high degree of connectivity between the caudate-putamen and the neocortex ${ }^{1,9,11,18}$. The striatum, like the neocortex, is a functionally heterogeneous structure with respect to behavior. For example, the dorsolateral caudate is involved in skilled limb use and the ventrolateral caudate is involved in mouth and tongue use, a relationship that parallels the relation between the dorsofrontal cortex and limb use and the ventrolateral frontal cortex and mouth and tongue use ${ }^{28,43}$. Third, damage to the cortex is known to produce transitory changes in the physiology of the caudate putamen. Deuel and Collins ${ }^{10}$ have reported ipsilateral depression and subsequent recovery of local glucose utilization in the striatum of monkeys 
recovering from contralateral neglect induced by unilateral neocortical injury. The changes in glucose utilization were mainly seen in the striatum and motor nuclei of the thalamus, but not in the remaining cortex. In addition, there are a number of behavioral and neurochemical studies that suggest catecholamine neurotransmission in the striatum may be depressed in the early postsurgical period, but may eventually return to normal ${ }^{3,21,33,34}$. Consistent with this, there is a substantial literature showing that recovery from cortical injury can be enhanced by amphetamine or retarded by haloperidol, drugs that are known to alter dopamine (DA) neurotransmission in the caudate-putamen ${ }^{7,12}$.

The idea that neocortical injury may transiently alter DA neurotransmission in the caudate-putamen, and thus contribute to the pattern of behavioral deficits and subsequent recovery of function, was investigated in the experiments reported here. Cortical injury consisted of nearly complete removal of the neocortex unilaterally. Amphetamine-induced rotational behavior was used to measure recovery, because acute ipsilateral bias and chronic contralateral bias in rotational asymmetries are produced by unilateral neocortical damage ${ }^{16}$. On the basis of evidence that DA agonists influence these rotational biases, such changes have been postulated to involve DA function ${ }^{2,16,32}$. Changes in these behavioral asymmetries over time following neocortical damage were related to changes in dopaminergic activity, as indicated by measures of both the postmortem tissue concentration of striatal DA and the extracellular concentration of striatal DA, assessed with microdialysis.

\section{MATERIALS AND METHODS}

\section{Subjects}

One hundred and twenty-nine adult male rats $(300-400 \mathrm{~g})$ derived from the Long-Evans strain, and raised at the University of Lethbridge, were used as subjects. They were housed in pairs on a $14: 10 \mathrm{~h}$ light-dark cycle (lights on $08.00 \mathrm{~h}$ ), and had free access to food and water. One-hundred and six rats were used in Expt. 1 and 23 rats were used in Expt. 2 (see below).

\section{Surgery}

For hemidecortication and implantation of dialysis probes, the animals were anesthetized with sodium pentobarbital (40-65 mg/ $\mathrm{kg}$, i.p.). To produce hemidecortications, the cortex was exposed by unilateral removal of the dorsal aspect of the frontal and parietal bones. The left or right neocortex, side chosen randomly, was then removed by aspiration ${ }^{44}$. Animals were not prescreened for endogenous turning preferences ${ }^{22}$ to avoid sensitization produced by amphetamine ${ }^{35}$.

If the animal was also to receive microdialysis probes (Expt. 2), a 2-mm-wide strip of bone adjacent to the coronal suture was left as an island onto which a dialysis probe could be cemented. Trephines were drilled for bilateral stereotaxic insertion of dialysis probes into the corpus of each striatum (coordinates from bregma: anterior $0.5 \mathrm{~mm}$, lateral $3.0 \mathrm{~mm}$, ventral $7.0 \mathrm{~mm}$ from the skul surface, with bregma and lambda horizontal ${ }^{27}$ ). Four anchor screws were secured to the intact dorsal frontal and parietal bones, and the dialysis probes were lowered and cemented in place with dental acrylic.

Expt. 1: Effects of hemidecortication on rotational asymmetries and the postmortem tissue concentrations of monoamines in the striatum

Measures of rotational asymmetries

In order to prevent a conditioned rotational bias due to previous amphetamine experience independent groups of rats received hemidecortication and were then given one test for rotational behavior on either days $2(n=12), 4(n=16), 11(n=10), 31(n=15)$ or $121(n=30)$ after surgery. Additional groups of rats with no lesion were tested on days $2(n=14)$ and $121(n=24)$. Amphetamine sulfate $(1.5 \mathrm{mg} / \mathrm{kg})$ weight of salt, s.c.) induced rotations were quantified in automated spherical rotometers ${ }^{35}$, similar to those described by Greenstein and Glick ${ }^{19}$. The rotometers were interfaced with a microprocessor which recorded every $1 / 4$ turn $\left(90^{\circ}\right)$ made to the right or left during each 5 -min interval. From these data total rotations were calculated, which are defined as the total number of complete turns ( 4 consecutive $1 / 4$ turns in the same direction) ipsilateral and contralateral to the lesion.

\section{Assay of striatal tissue}

On the day following its behavioral test, each animal was killed by decapitation and its brain was removed rapidly and placed in ice-cold saline (30-45 s). The brain was then placed in a chilled cutting block for sectioning. A tissue punch was used to obtain samples from the corpus of anterior dorsal striatum ${ }^{20}$. The postmortem tissue concentrations of striatal DA 3,4 dihydroxyphenylacetic acid (DOPAC), homovanillic acid (HVA), 5-hydroxyindoleacetic acid (5-HIAA), and 5-hydroxytryptamine (5-HT) were determined by high performance liquid chromatography (HPLC) and electrochemical detection, as described previously ${ }^{37}$.

Expt. 2: Effects of hemidecortication on rotational asymmetries and the extracellular concentrations of DA and monoamine metabolites in vivo

Rats were assigned to one of 3 treatment conditions. (1) Acute group $(n=8)$. Immediately following hemidecortications a dialysis probe was lowered into the striatum in each hemisphere and after the dental cement had cured, the animal was placed into the test chamber, while anesthetized. Collection of dialysate began $45 \mathrm{~min}$ after hemidecortication. (2) Chronic group $(n=8)$. The rats were hemidecorticated and then were returned to their home cages to recover for 60 days. After this, a dialysis probe was implanted into the striatum in each hemisphere as described above, and then the rat was left in the test chamber overnight. Therefore, collection of dialysate in this chronic group began about $18 \mathrm{~h}$ after probe implantation. (3) Control group $(n=7)$. Control rats were implanted with dialysis probes in each hemisphere in the same way but they did not receive a neocortical lesion.

\section{Construction of dialysis probes and microdialysis procedure}

The dialysis probes have been described previously ${ }^{5,38,39}$. They were of a concentric design with an outer diameter of $250 \mu \mathrm{m}$ and a $4 \mathrm{~mm}$ long dialysis surface at the tip. The outlet line was made of fused silica capillary tubing (i.d., $75 \mu \mathrm{m}$ ), which led to a collection vial attached to the tether, about $35 \mathrm{~cm}$ above the animal. From this location, the collection vials could be quickly exchanged without disturbing the animals.

The pump speed was set at $1.5 \mu \mathrm{l} / \mathrm{min}$ during probe implantation, and was maintained at that speed during all sample collection intervals. All samples were collected over 20 min intervals and assayed within $30 \mathrm{~min}$, using HPLC and series oxidative-reductive electrochemical detection ${ }^{5,6}$.

The probes were tested for in vitro recovery prior to use $\mathrm{e}^{39}$ and dialysate values were corrected for recovery. The average $( \pm$ S.E.M.) relative recovery values for the probes used in Expt. 2 were: DA, $23.82 \pm 0.33 \%$; DOPAC, $21.51 \pm 0.27 \%$; HVA, 20.26 
$\pm 0.31 \%$; and 5-HIAA. $21.46 \pm 0.33 \%$.

Dialysis experiments on days $1-3$ after hemidecortication (acute group)

Dialysis samples were collected for 3 days following probe implantation, including the day of hemidecortication. On day 1 , four consecutive 20 -min samples were collected beginning $45 \mathrm{~min}$ after probe implantation (the animals were somnolent due to anesthesia for the first 4 samples collected after probe implantation), and one additional 20 -min sample was collected beginning $7.5 \mathrm{~h}$ after probe implantation. On both days 2 and 3 after probe implantation, at least three $20-\mathrm{min}$ baseline samples were collected. The animals were then given $1.5 \mathrm{mg} / \mathrm{kg}$ of $\mathrm{D}$-amphetamine sulfate $(3 \mathrm{mg} / \mathrm{ml}$, weight of the salt, s.c. in the neck) and 6 additional 20 -min samples were collected, beginning immediately after the injection of amphetamine.

Dialysis experiments on day 60 after hemidecortication (chronic group)

Dialysis probes were implanted 60 days after hemidecortication. The rats were then placed in the test chamber and left overnight. The dialysis experiment began the next day, exactly as described above for day 2 in the acute group.

\section{Measures of rotational asymmetries}

In Expt. 2 the animals were videotaped during testing using a Sony camera and Betamax recorder (with variable speed play-back features). Behavior was subsequently analyzed by an observer blind to the treatment conditions. The videotapes were viewed at two times normal speed and the number of $90^{\circ}$ turning movements made ipsilateral or contralateral to the lesion were summed during each of the 20 -min dialysis collection intervals, including baseline and amphetamine conditions. In the case of normal animals one hemisphere was arbitrarily designated as the sham-lesion hemisphere.

\section{Histology for probe placements}

At the end of each experiment the tubing leading to the dialysis probes was cut at the level of the dental cement 'cap' and the rats were deeply anesthetized and then perfused through the heart with a solution of $0.9 \% \mathrm{NaCl}$ and $10 \%$ formalin. The brains were removed and the extent of neocortical damage was drawn on prepared maps of the neocortex. The brains were subsequently fixed in $30 \%$ sucrose and formal-saline and then cut into $40-\mu \mathrm{m}$ sections. Representative sections were mounted on glass slides and stained with Cresyl violet to confirm dialysis probe placement and the extent of the neocortical lesion.

\section{RESULTS}

\section{Extent of neocortical damage}

The animals in Expt. 1 had extensive damage to the entire neocortex, similar to that described previously by Whishaw et al. ${ }^{45}$ (Fig. 2). Most of the neocortex down to the rhinal fissure, the midline cingulate cortex, and the medial frontal cortex was removed. In some rats, small strips of neocortex were spared along the edge of the rhinal fissure. There was no direct damage to underlying structures such as the hippocampus, thalamus, or caudate-putamen. The extent of the lesions in the rats that underwent dialysis (Expt. 2) is illustrated in Fig. 1. Rats tested on days 1-3 following surgery (acute group) are shown in Fig. 1A and rats tested after 60 days of re- covery (chronic group) are shown in Fig. 1B. All animals sustained similar and extensive loss of neocortex with little or no damage extending into pyriform cortex. striatum, thalamus or hippocampus. In different animals small remnants of cortex were spared along the rhinal fissure, cingulate cortex, or posterior cortex. The only consistently spared neocortical tissue was below the strip of skull bone bordering the coronal suture, which was left to secure the dialysis probes, but in a few animals even this was removed (e.g., rats 7 and 66).

\section{Expt. 1: Effects of hemidecortication on rotational asym- metries and the postmortem tissue concentrations of monoamines in the striatum}

\section{Amphetamine-induced rotational behavior as a function of time following hemidecortication}

The relationship between amphetamine-evoked rotational behavior and the postmortem tissue concentrations of striatal monoamines in groups of hemidecorticate rats studied at 2-121 days after surgery is shown in Fig. 2. The behavioral and biochemical results are represented by an asymmetry index, which was calculated by subtracting the values corresponding to the hemisphere ipsilateral to the lesion from the values corresponding to the hemisphere contralateral to the lesion. Therefore, an asymmetry index of zero indicates the absence of laterality. Fig. 2 (top) shows the rotational bias evoked by amphetamine as a function of time following hemidecortication. The control group (closed circle) did not show significant laterality in this situation, $t_{25}=1.19$, $P=0.24$. The absence of an asymmetry in the control group might be expected since the 'ipsilateral' hemisphere in this group was designated randomly. Two days after hemidecortication, however, animals showed a marked asymmetry in behavior, characterized by a rotational bias towards the lesion side. This asymmetry in behavior was not present at any other time following the lesion (Fig. $2 ; F_{5,103}=8.72, P<0.001$, follow-up Newman-Keuls, $P<0.05$ ). Although there was a slight bias towards contraversive turning at 31 and 121 days postlesion ( $t$ s $>2.2, P<0.05$ ), the asymmetry in these animals did not differ significantly from that in the animals with no lesion.

\section{Postmortem tissue concentrations of striatal monoamines in hemidecorticate rats as a function of time following hemidecortication}

There was no significant difference in any of the asymmetry measures between days 2 and 121 in the individual control groups, and therefore their data were pooled for subsequent analysis. The asymmetry index for control animals is indicated by the closed circles in Figs. 2 


\section{A. Acute}
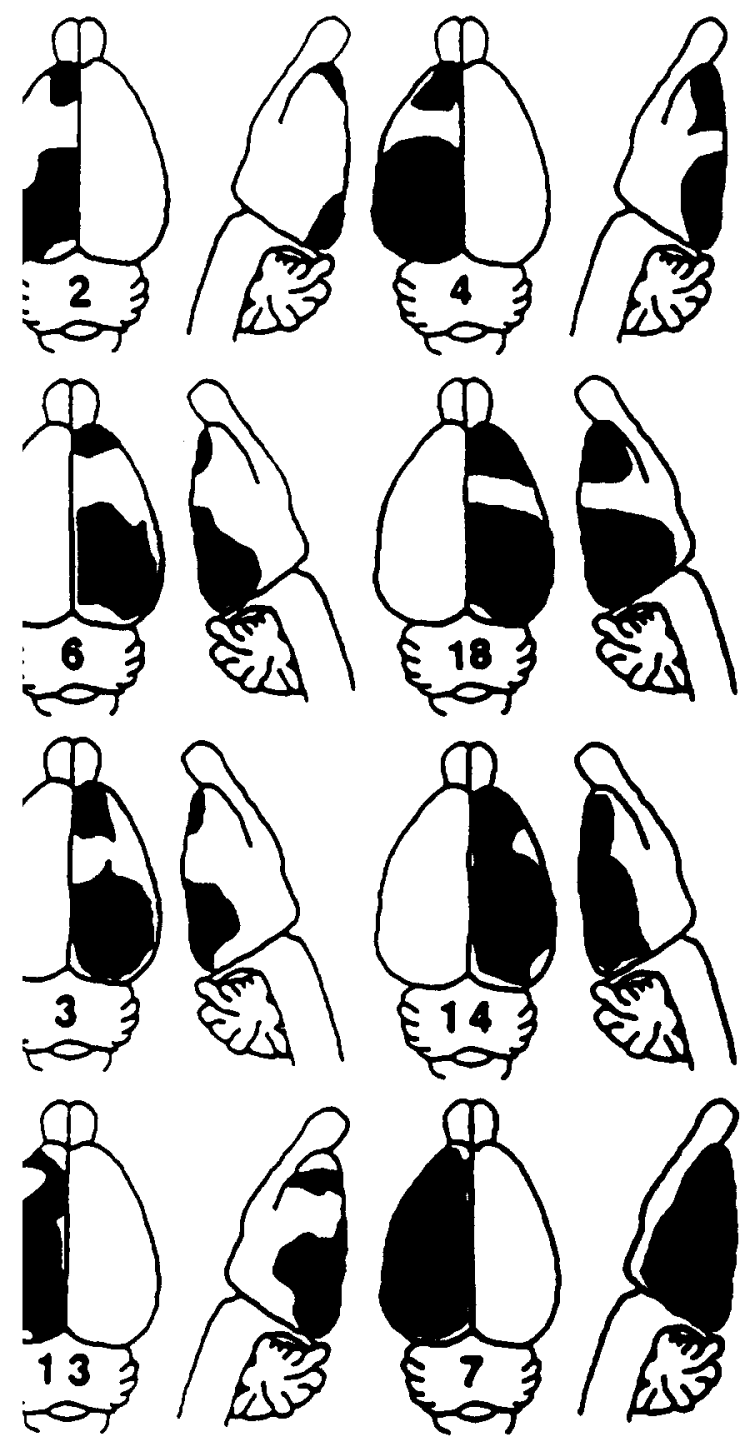

1. Dorsal and lateral surface recontructions of lesions in 8 rats (two left columns, A) on which dialysis was performed during the first $s$ following hemidecortication and 8 rats (two right columns, B) on which dialysis was performed 60 days following hemidecortications. $\mathrm{e}$ loss is shown in solid black. The strip of spared tissue in the ablated hemisphere underlay the bone to which the dialysis probes were red.

3. Postmortem DA, DOPAC, HVA and 5-HIAA $s$ in the control group were assessed in relation to the randomly designated hemisphere (see above) as as the preferred (dominant) direction of turning. e were no significant differences for these values y either designation, $t \mathrm{~s}<2, P>0.05$.

1ere was no significant asymmetry in striatal DA or 'AC at any point in time following hemidecortica$\mathrm{DA}, F_{5,83}=0.84$ and DOPAC, $F_{5,73}=0.98, P \mathrm{~s}>$ , see Fig. 2). The asymmetry indices for DA and 'AC in hemidecorticate animals also did not differ those obtained in the control group at any point.

\section{B. Chronic}
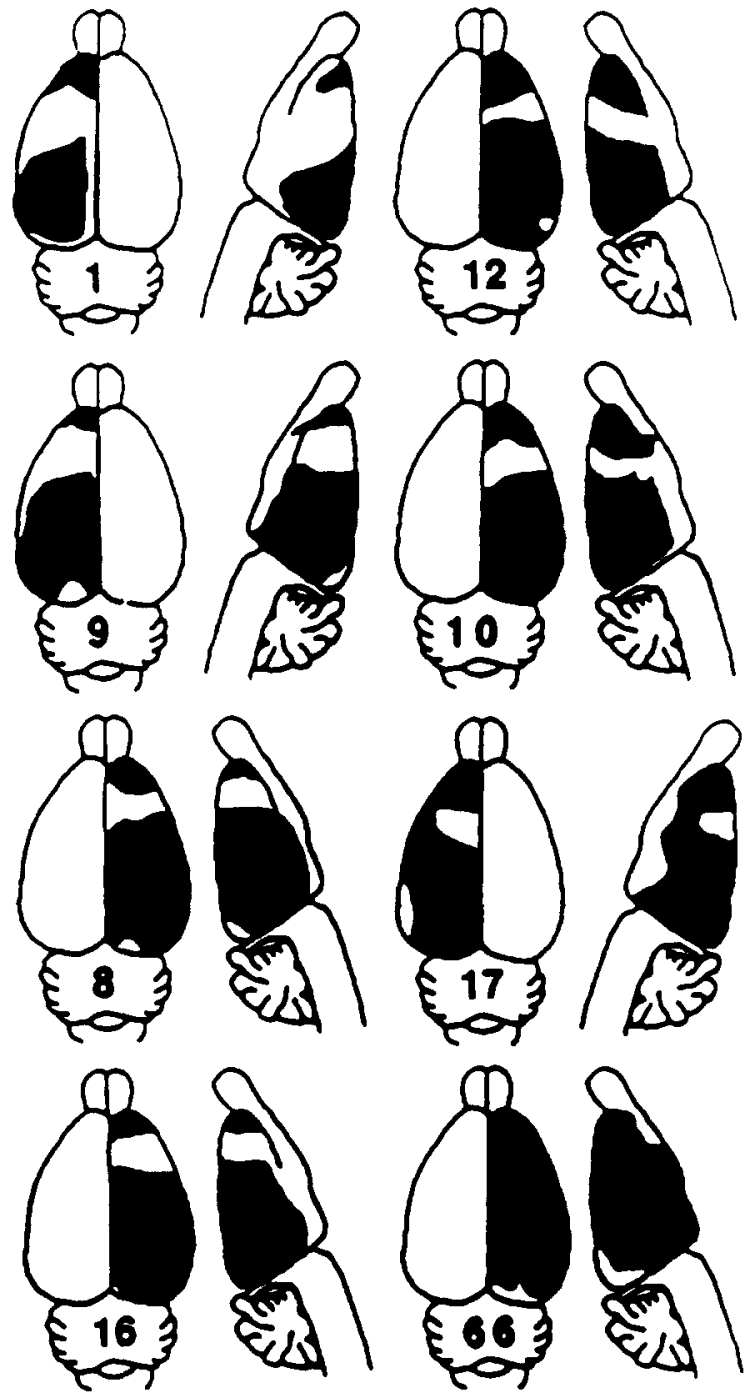

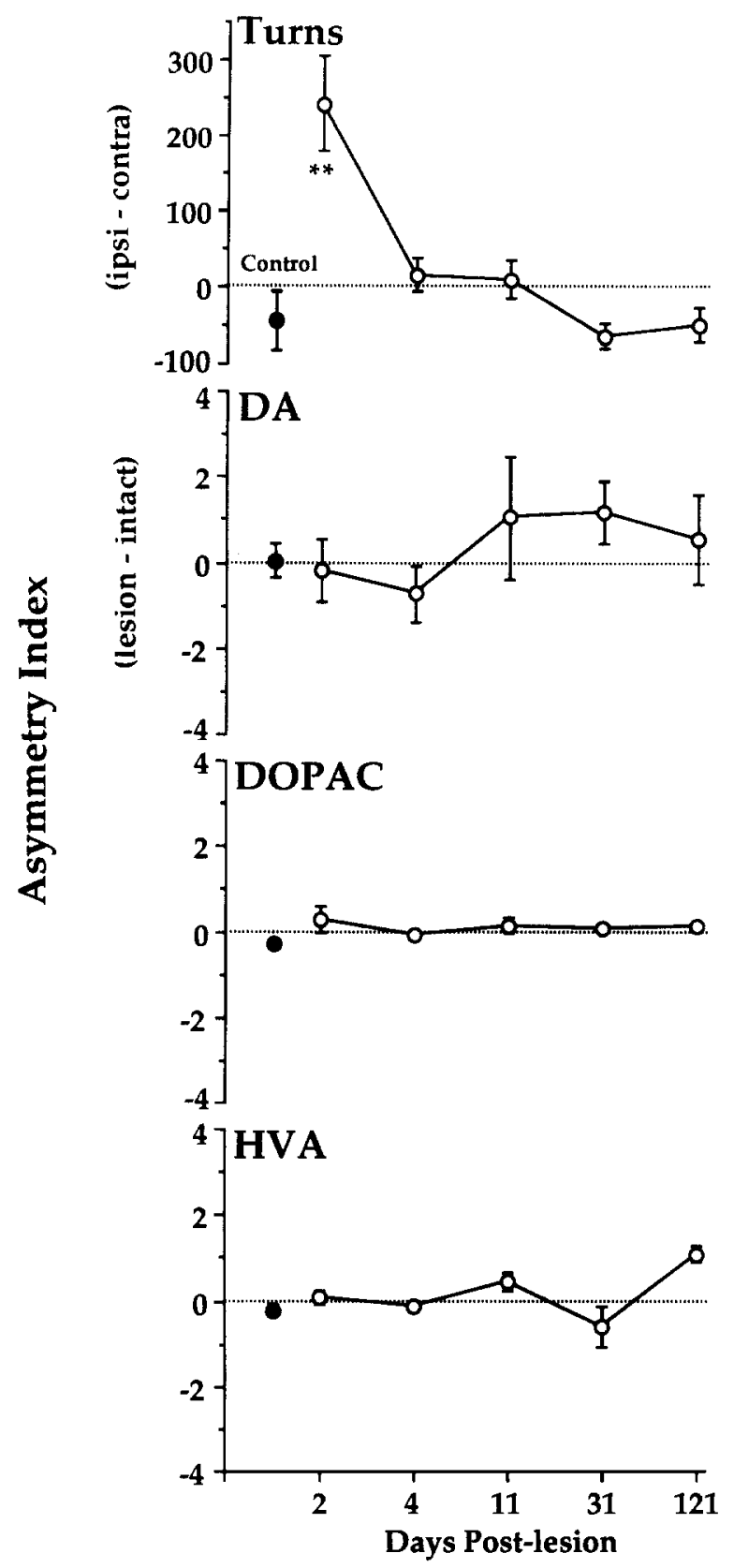

Fig. 2. Top: average ( \pm S.E.M.) asymmetry indices for turning behavior, calculated by taking the difference between the number of turns ipsilateral to the hemidecortication minus contralateral turns made after amphetamine administration in separate groups of rats tested at different postsurgery intervals. Hemidecorticate sample sizes: day 2,12 ; day 4,16 ; day 11,10 ; day 31,15 ; and day 121,30 (day $2=$ day following surgery). In controls $(n=26)$ the average $( \pm$ S.E.M.) number of ipsilateral turns was $91.57 \pm 20.40$ and contralateral turns was $136.66 \pm 25.35$. Average ( \pm S.E.M.) asymmetry indices are also shown for postmortem tissue concentration tissue levels of DA (upper middle), DOPAC (lower middle) and HVA (bottom). Tissue was obtained the day following testing with amphetamine and between 2 and 121 days after hemidecortication. The asymmetry index was calculated by subtracting the tissue concentration ( $\mathrm{ng} / \mathrm{mg}$ wet brain) on the lesion side from that on the intact side. Hemidecorticate sample sizes: day 2, 16 (control, DA18, DOPAC and HVA-6); day 4, 16; day 11,10 ; day 31,15 ; and day 121,16 . Thus, a positive number reflects greater ipsilateral turning or a higher concentration of DA, DOPAC, or HVA in the damaged hemisphere. In controls the average ( $\mathrm{ng} / \mathrm{mg} \pm \mathrm{S}$.E.M.) postmortem tissue concentrations were: DA. 14.60 \pm 0.35 ; DOPAC, $2.19 \pm 0.07 ;$ HVA, $1.00 \pm 0.07$.
TABLE 1

Mean \pm S.E.M. metabolitelneurotransmitter ratios in posimortem tissue from the striatum (caudate putamen) in controls and from the intact and lesion hemispheres from rats with unilateral neocortical damage after various time intervals of recovery (days)

$\begin{array}{llll} & \text { DOPAC/DA } & \text { HVA/DA } & \text { 5-HIAA/S-HT } \\ \text { Control } & 0.16 \pm 0.01 & 0.075 \pm 0.01 & 0.79 \pm 0.06 \\ \text { Intact } & & & \\ \text { 2 days } & 0.15 \pm 0.01 & 0.08 \pm 0.01 & 1.26 \pm 0.10 \\ \text { 4 days } & 0.12 \pm 0.01 & 0.11 \pm 0.01 & 1.80 \pm 0.09 \\ \text { 11 days } & 0.01 \pm 0.01 & 0.08 \pm 0.01 & 1.67 \pm 0.21 \\ \text { 31 days } & 0.11 \pm 0.01 & 0.11 \pm 0.04 & 1.04 \pm 0.04 \\ \text { 121 days } & \text { n.a. } & \text { n.a. } & 1.10 \pm 0.08 \\ \text { Lesion } & & & \\ \text { 2 days } & 0.19 \pm 0.05 & 0.10 \pm 0.03 & 2.05 \pm 0.27^{*} \\ \text { 4 days } & 0.12 \pm 0.01 & 0.10 \pm 0.01 & 2.29 \pm 0.18 \\ \text { 11 days } & 0.10 \pm 0.01 & 0.11 \pm 0.01 & 1.81 \pm 0.25 \\ \text { 31 days } & 0.11 \pm 0.01 & 0.06 \pm 0.01 & 0.92 \pm 0.21 \\ \text { 121 days } & \text { n.a. } & \text { n.a. } & 1.372 \pm 0.10\end{array}$

${ }^{*} P<0.01$, relative to control values. n.a., not available.

index was $>0$ ) and on day 121 the asymmetry index was significantly less than zero. The asymmetry indices from neither the day 31 and day 121 groups differed significantly from the control value. For 5-HIAA the asymmetry index was significantly greater than zero 2 days after

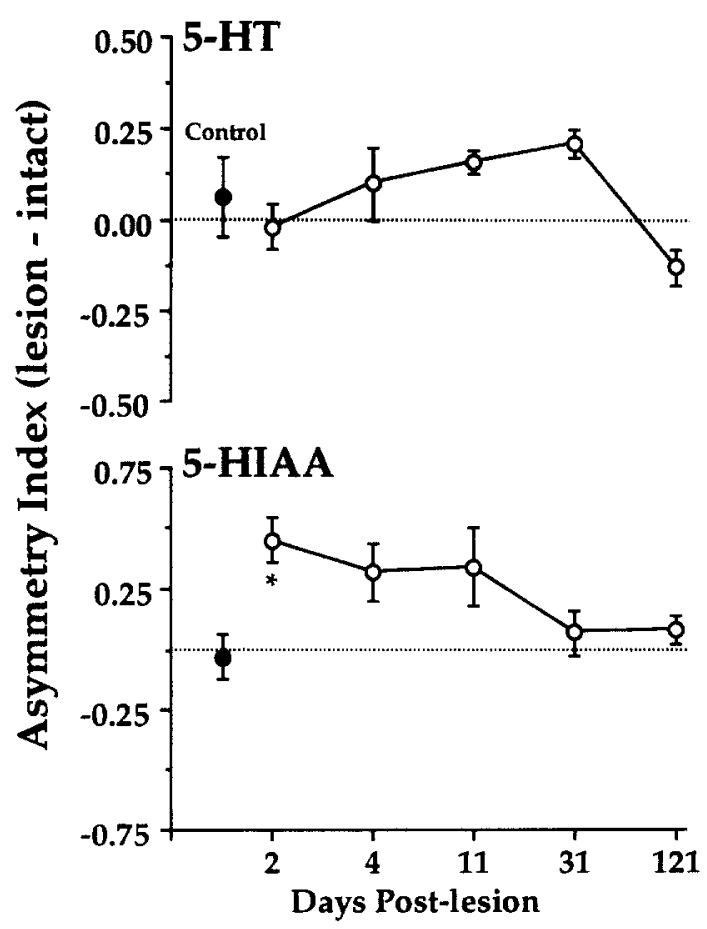

Fig. 3. Average ( \pm S.E.M.) asymmetry indices, as described in Fig. 2, for 5-HT (top) and 5-HIAA (bottom) measured between 2 and 121 days after hemidecortication. In controls the average $(\mathrm{ng} / \mathrm{mg} \pm$ S.E.M.) postmortem tissue levels for $5-\mathrm{HT}$ was $0.75 \pm 0.07$ and for 5 -HIAA was $0.57 \pm 0.05$. Refer to Fig. 2 for sample sizes. Note the increase in 5-HIAA on the lesion side on day 2 post-lesion relative to control levels. 
A. Control
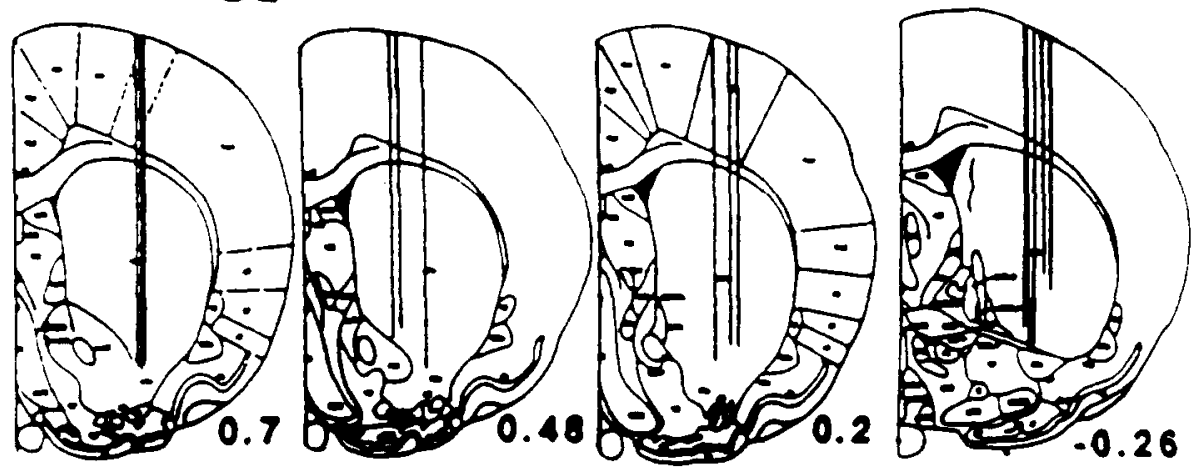

B. Intact
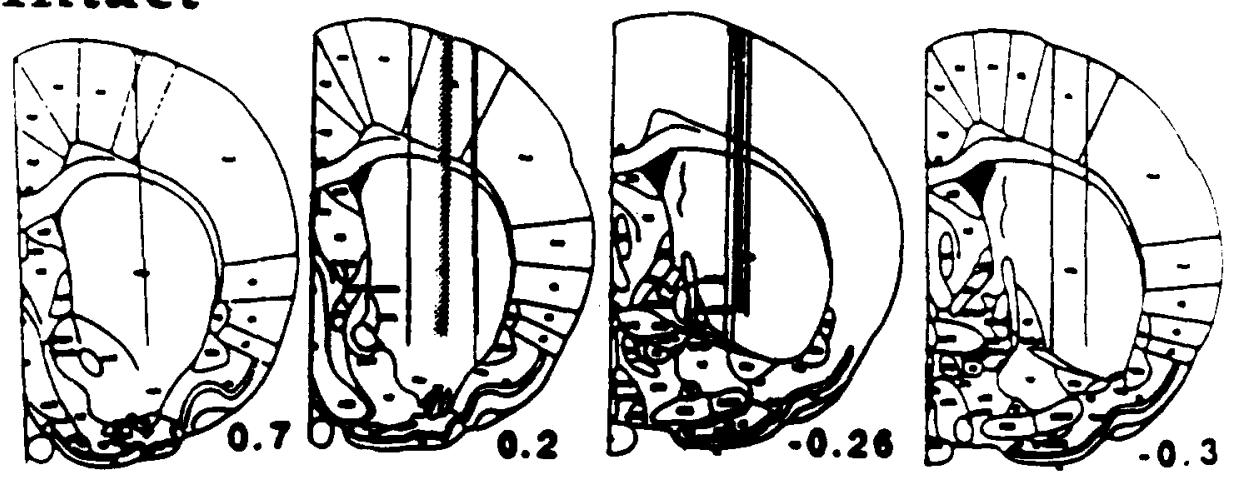

\section{Acute}

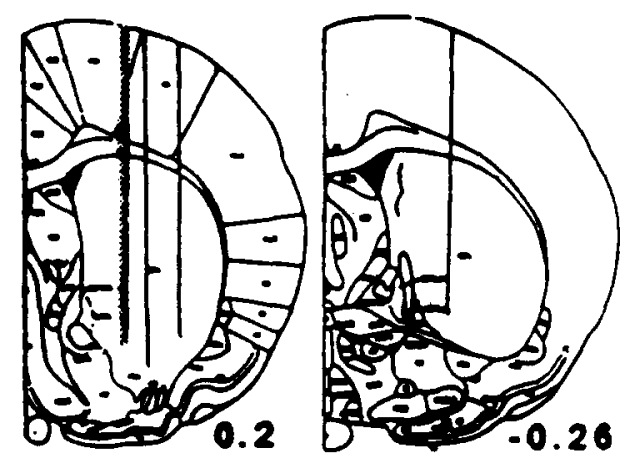

\section{Chronic}

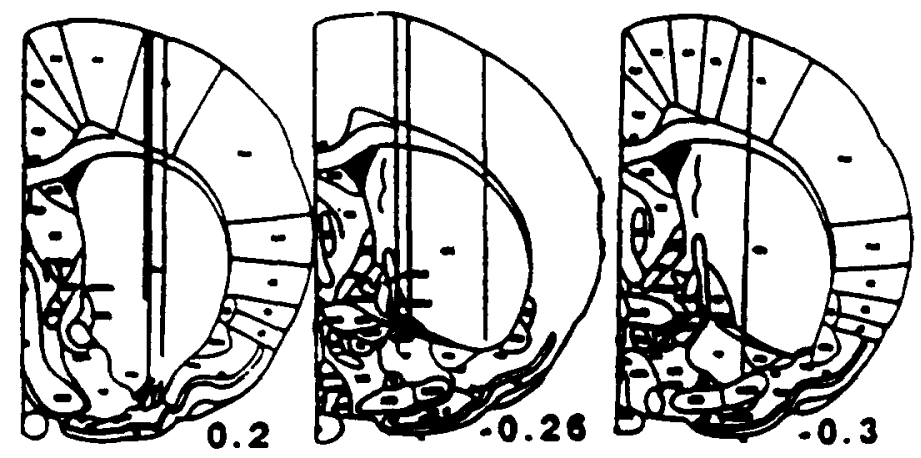

Fig. 4. Coronal sections showing the location of the dialysis probes. A: probe tracts from control rats. B: probe tracts on the intact side of rats tested acutely and chronically following hemidecortication. The shaded bar located at the level of $+0.2 \mathrm{~mm}$ from bregma represents the area of implantation for 6 probes. C: probe tracts on the lesion side of rats on which dialysis was performed during the first 3 days following hemidecortication (acute group). The shaded bar located at the level of $+0.2 \mathrm{~mm}$ from bregma represents the area of implantation for 5 probes. D: probe tracts from the lesion side for animals on which dialysis was performed 60 days following hemidecortication (chronic group). Histological verification of probe placement for one animal in this latter group was not possible. (After Paxinos and Watson ${ }^{27}$ ). Note that the dialysis surface includes only the most ventral $4 \mathrm{~mm}$ of tract shown here. 
hemidecorticaton $(P<0.05)$, but this effect was transient, and the asymmetry indices between days 4 and 121 did not differ from zero.

An analysis of metabolite/neurotransmitter ratios was conducted to determine wheter there were asymmetrical changes in DA or 5-HT 'utilization' as a function of time following hemidecortications (Table I). DOPAC/DA and HVA/DA ratios did not vary as a function of time and did not differ from control values at any point in time following hemidecortications. In contrast, Table I shows that there was a significant effect of hemidecortication on 5-HIAA/5-HT ratios, $F_{1,136}=10.74, P<0.01$. The ratio of 5-HIAA/5-HT in the striatum ipsilateral to the lesion was significantly elevated 2 days following hemidecortication, days $F_{4,136}=14.40, P<0.001$, but not at any other point in time. This immediate postlesion in crease in 5-HIAA/5-HT values from the damaged hemisphere is in agreement with the enhancement in tissue 5-HIAA levels observed on day 2 postlesion (see Fig. 3, bottom).

Experiment 2: Effects of hemidecortication on rotational asymmetries and the extracellular concentrations of $D A$ and monoamine metabolites in vivo

\section{Location of dialysis probes}

The location of the dialysis probes within the striatum are illustrated in Fig. 4. The distribution of probes within the striatum of the control, acute (day 2), and chronic (day 60) groups was quite similar. We were concerned that changes in brain shape following hemidecortication might result in systematic displacement of the dialysis probes. The histological results, however, indicated that probe placements in the different groups overlapped extensively. An analysis of basal DA in control animals did

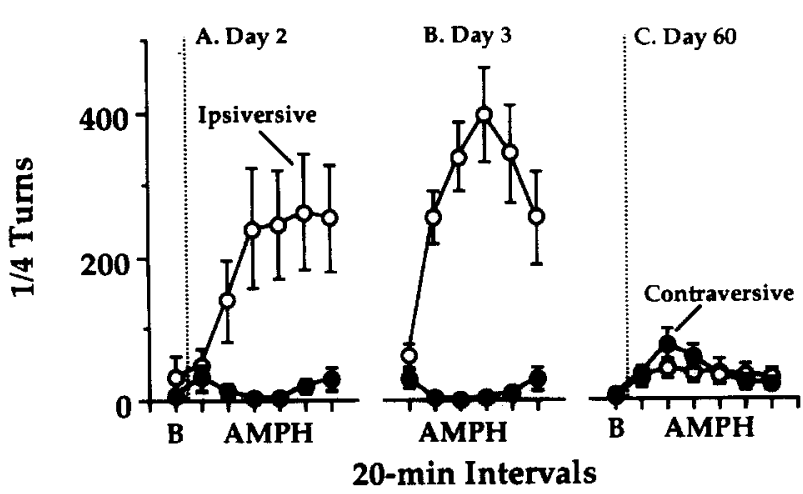

Fig. 5. Average ( \pm S.E.M.) number of $1 / 4$ turns made ipsilateral to the lesion hemisphere and contralateral to the lesion hemisphere during baseline (B) and following an amphetamine (AMPH) challenge in hemidecorticate rats tested on days 2, 3 or 60 following hemidecortication. Note the marked ipsiversive rotational bias fol lowing amphetamine on days 2 and 3 following hemidecortication. show that the basal extracellular concentration of DA was significantly higher in the anterior striatum, relative to more posterior sites $(r=0.57, P<0.03)$, which is consistent with previous studies ${ }^{47}$. The range of locations of probes in the hemidecorticate groups was not as great as in the control group and there was no significant correlation between placement and basal extracellular concentrations of DA in these animals.

Rotational behavior in animals during the dialysis experiments

Fig. 5 illustrates the extent of the asymmetry in behavior produced by amphetamine in hemidecorticate animals tested on days $2-3$ following their lesion, and then in a separate group tested 60 days after the lesion. Note
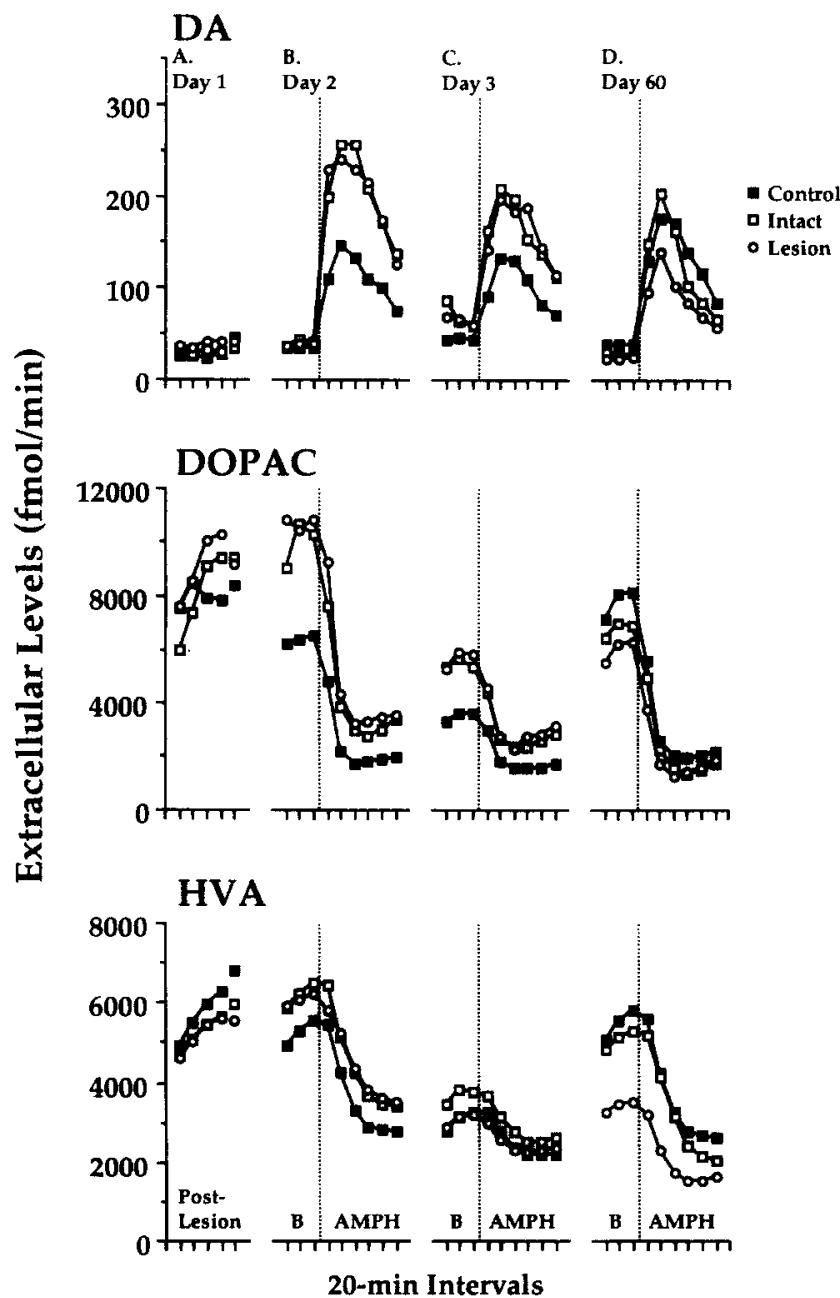

Fig. 6. The extracellular concentrations (mean \pm S.E.M.) of dopamine (DA, top), 3,4-dihydroxyphenylacetic acid (DOPAC, middle) and homovanillic acid (HVA, bottom) from the striatum of control animals and from each striatum (intact side and lesion side) of the hemidecorticate animals. Collection of dialysate began 45 min following surgery (day 1) and continued for an additional 2 days. A separate group of animals was tested 60 days following hemidecortication (day 60 ). Amphetamine $(1.5 \mathrm{mg} / \mathrm{kg} \mathrm{s.c.,} \mathrm{dotted}$ vertical line) was given on days 2 and 3 and 60 . 


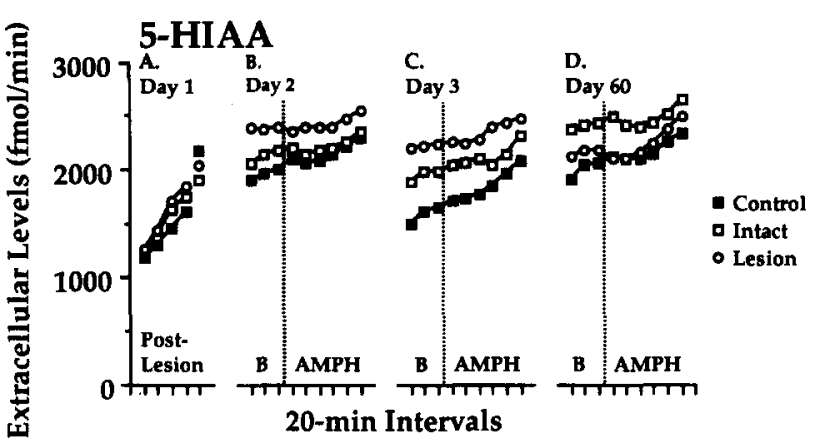

Fig. 7. The extracellular concentration (mean \pm S.E.M.) of 5-hydroxyindoleacetic acid (5-HIAA) collected across 3 days immediately following hemidecortication and on day 60 . On days 2 and 3 and 60 , the rats were given amphetamine $(1.5 \mathrm{mg} / \mathrm{kg}$ s.c., dotted vertical line).

that behavior was recorded at the same time as the animals were undergoing microdialysis. For the control rats, one hemisphere was arbitrarily designated as the 'lesion' side and under these conditions they showed no group rotational bias (not shown in Fig. 5). For the hemidecorticate rats, on day 2 (Fig. 5A) and on day 3 (Fig. 5B) there were no significant differences in ipsiversive vs contraversive turns under baseline conditions, i.e. prior to amphetamine (day 3 baseline not shown). After amphetamine, however, hemidecorticate animals showed a striking asymmetry in behavior, making many more turns in the ipsiversive direction than in the contraversive direction on both day 2 , side $F_{1,14}=10.25, P<$ 0.006 , and day 3 , side $F_{1,14}=43.42, P<0.001$, which is consistent with the results shown in Fig. 1. On days 2 and 3 following hemidecortication 87 and $95 \%$ of the turns, respectively, were made towards the side of the lesions (ipsiversive). In contrast, by 60 days after hemidecortication there was no longer any significant asymmetry in behavior either before or after amphetamine administration, $F<2, P>0.05$, and there was no difference in the number of ipsiversive or contraversive turns made by control vs hemidecorticate animals.

Extracellular DA, DOPAC, HVA and 5-HIAA as a function of time following hemidecortication

Fig. 6 illustrates the mean extracellular concentrations of DA, DOPAC and HVA measured: (A) for up to $8 \mathrm{~h}$ beginning $0.75 \mathrm{~h}$ after probe implantation (day 1 ), when the animals were still recovering from anesthesia; ( $\mathrm{B}$ and C) over the next 2 days (days 2 and 3), both before ( 3 baseline samples) and after a challenge injection of amphetamine; and (D) in a separate group of animals tested 60 days after hemidecortication.

On day 1 , between 0.75 and $8 \mathrm{~h}$ after probe implantation, the basal extracellular concentration of DA was stable, and there was no effect of hemidecortication ap- parent at this time. In contrast, there was a significant increase in the extracellular concentration of DOPAC and HVA between 0.75 and $8 \mathrm{~h}$ after probe implantation, although again, no effect of hemidecortication was apparent (Fig. 6A).

Effects of hemidecortication on the extracellular concentration of DA, DOPAC and HVA were apparent on subsequent days of testing, but varied as a function of time si-ice t. lesion. First, for DA, there was no effect of hemidecortication during baseline testing (prior to amphetamine) on any day of testing; that is, there was no difference in the extracellular concentration of DA between the intact and lesion side in hemidecorticate animals, or between hemidecorticate and control animals, on days 2,3 or 60 . The amphetamine challenge produced a significant increase in the extracellular concentration of DA in all groups, but despite the fact that there was a strong asymmetry in amphetamine-induced rotational behavior on days 2 and 3 (see Fig. 5), there was no asymmetry in amphetamine-induced DA release at this time: that is, the intact and lesion sides did not differ on either days 2 or 3 (Fig. 6B, C). There was, however, a significant effect of hemidecortication on amphetamine-stimulated DA release. On day 2, amphetamine produced a significantly greater increase in extracellular DA in hemidecorticate animals (intact and lesion sides pooled) than in control animals with no lesion, $F_{1,28}=4.35, P<0.046$. This difference in amphetaminestimulated DA release between hemidecorticate and control animals also approached statistical significance on day $3, F_{1,22}=2.88, P=0.10$, but after 60 days of recovery there was clearly no effect of hemidecortication on amphetamine-stimulated DA release (Fig. 6D). Thus, amphetamine produced a greater increase in the extracellular concentration of striatal DA in hemidecorticate animals than in control animals soon after the lesion, but not following 60 days of recovery, but there was no asymmetry in basal or amphetamine-stimulated DA release at any time following hemidecortication.

An effect of hemidecortication on the extracellular concentration of DOPAC was also apparent. Again, there was no asymmetry in extracellular DOPAC (i.e., the intact and lesion sides did not differ; Fig. 6) at any point in time following the lesion, either before or after amphetamine. The extracellular concentration of DOPAC was significantly higher in both hemispheres of hemidecorticate animals, relative to control animals, on days 2 and 3 following the lesion (Fig. 6, $F \mathrm{~s}=>6.00$, $P<0.05$ ). By day 60 , this effect was no longer present. For HVA, none of the comparisons on days 2 and 3 were statistically significant, although by day 60 the extracellular concentration of HVA was significantly lower on the lesion side than on the intact side, or in control an- 
imals, both before and after amphetamine (Fig. $6, F_{\mathrm{s}_{2,27}}$ $>7.00, P \mathrm{~s}<0.005$, Newman-Keuls, $P<0.05)$.

The effect of hemidecortication and amphetamine on the extracellular concentration of the serotonin metabolite, 5-HIAA, is shown in Fig. 7. There were no significant group differences (side or hemidecorticate vs control) at any point in time following the lesion, $F \mathrm{~s}=<$ $1.95, P$ s $>0.05$. There was, however, a progressive increase in 5-HIAA in all groups between 0.75 and $8 \mathrm{~h}$ immediately following probe implantation, and following the amphetamine challenge on all days of testing, $F \mathrm{~s}>$ $8.0, P<0.001$.

\section{DISCUSSION}

Hemidecortications produced a marked asymmetry in amphetamine-induced rotational behavior, but this effect was only transient. For the first 2-3 days following hemidecortication, amphetamine caused rotational behavior preferentially toward the side of the lesion. This result confirms a number of previous reports ${ }^{16,29,41}$. This asymmetry in behavior disappeared within 4 days and was no longer apparent between 4 and 121 days following hemidecortication, also confirming a previous report ${ }^{41}$. As discussed in the introduction, it was hypothesized that the asymmetry in behavior seen following hemidecortication may be due to an asymmetry in DA neurotransmission in the striatum, and recovery of behavioral symmetry to a recovery of symmetry in striatal neurotransmission. There was no indication, however, of any relationship between the behavioral asymmetry induced by hemidecortication and an asymmetry in DA neurotransmission, as indicated by either measures of DA utilization in postmortem tissue, or measures of amphetamine-stimulated DA release using in vivo microdialysis. The dissociation between behavior and striatal DA neurotransmission was most striking in the dialysis experiment. Amphetamine produced marked ipsiversive rotational behavior 2 days after hemidecortication, but in the same animals, at the same time, there was no asymmetry in amphetamine-induced striatal DA release.

There was some indication of a relationship between an asymmetry in the 5-HT input to the striatum and the behavioral asymmetry produced by hemidecortication. The postmortem tissue concentration of 5-HIAA and 5-HIAA/5-HT ratios were significantly elevated in the lesion hemisphere 2 days following hemidecortication, but at longer recovery intervals this asymmetry in 5-HT metabolism was not present (nor was the behavioral asymmetry). Thus, the rotational bias may be due to changes in 5-HT. On the other hand, there was no asymmetry in the extracellular concentration of 5-HIAA determined with microdialysis, at any point in time follow- ing hemidecortication, which does not support the idea that an asymmetry in 5-HT neurotransmission is in volved. It should be acknowledged, however, that neither of these measures may accurately reflect 5-HT neurotransmission.

In addition, the present data cannot exclude the alternative hypothesis that the asymmetry in behavior is caused by other striatal changes produced by the le$\operatorname{sion}^{10.40}$. For example, changes in the activity of local interneuronal networks within the caudate nucleus may be important, and this idea is indirectly supported by observations in non-human primates that there is an initial depression and subsequent recovery of localized glucose utilization in the striatum following unilateral ablation to either frontal association cortex ${ }^{10}$ or motor and premotor cortical areas ${ }^{14}$. A number of other possibilities exist, such as that the behavioral asymmetry is due to changes in corticobulbar or corticospinal projections ${ }^{42}$, but the present data do not directly suggest any of these alternatives.

In the immediate postsurgical period $(0.75-8 \mathrm{~h})$, the extracellular concentration of DA, DOPAC, HVA and 5-HIAA appeared normal, relative to control animals that received no lesion. This is interesting, because the tissue damage produced by transient forebrain ischemia is reported to produce a dramatic (150 times baseline) increase in extracellular $\mathrm{DA}^{8,17}$. The effects of ischemia on extracellular DA are rather short lived (circa $40 \mathrm{~min}$ ), however, and in the present experiment we were not able to begin dialysis until $45 \mathrm{~min}$ postlesion. Thus, hemidecortication may have produced a short-lasting $(<$ $45 \mathrm{~min}$ ) increase in extracellular DA that had dissipated by the time sample collection began in the present experiment. This is unlikely, however, because transient ischemia also produces a dramatic increase in the extracellular concentration of DOPAC and HVA that persists for at least $1 \mathrm{~h}$, and such changes were not evident after hemidecortication. There was an increase in extracellular DOPAC and HVA immediately following probe implantation, which has been described previously ${ }^{36}$, and this occurred to an equal extent in both hemidecorticate and control animals.

The asymmetry in rotational behavior seen in hemidecorticate animals was very short-lived. It was only present for the first couple of days following the lesion, and was not evident at any other point in time up to 4 months later. This is consistent with other studies that have followed animals for up to 1 year after hemidecortications ${ }^{41}$. In contrast, Glick and Greenstein ${ }^{16}$ have suggested that frontal cortex damage produces a delayed striatal hyperactivity ipsilateral to the damage, based on the finding that after 15 to 30 days of recovery, rats rotated away from the side of the lesion. It is noteworthy 
that Glick and Greenstein ${ }^{16}$ used only 5 -min rotational tests, which contrasts with the 120 -min tests used here. Short tests may not reliably evaluate the full range of amphetamine-induced asymmetry. Bracha et al. ${ }^{4}$ have applied the Glick and Greenstein explanation to their observation that humans, who had suffered frontal and inferior parietal strokes, displayed a tendency to turn away from the direction of damage when studied months or years later. In monkeys, however, Kennard and Ec$\operatorname{tors}^{23}$ report an ipsilateral rotational bias a year after surgery. Thus, there is contradictory evidence concerning the chronic effects of lateralized neocortical damage on asymmetries in behavior. It is important to note, however, that the human and monkey results were obtained without drug treatments, and there is no independent evidence that these asymmetries in behavior are related to asymmetries in DA function. The present results reported here support the idea that circling behavior is not always caused by asymmetries in dopaminergic function.

Although there was no lateralized effect of hemidecortication on striatal DA neurotransmission, hemidecortication did have a pronounced effect on striatal DA neurotransmission. On days 2 and 3 following hemidecortication, amphetamine induced a greater increase in extracellular DA than in control animals, and the extracellular concentration of DOPAC was significantly elevated in the hemidecorticate group. These changes were transient, because they were not evident after 60 days of recovery. It is thought that DOPAC is formed primarily from DA that is metabolized intraneuronally, independent of DA release ${ }^{25,48}$. Thus, hemidecortication may have increased the size of the cytoplasmic pool of DA on days 2 and 3 following the lesion. Amphetamine is thought to preferentially release DA from this cytoplasmic pool by an accelerated exchange-diffusion process ${ }^{13}$, ${ }^{24}$. This suggests, therefore, that amphetamine may have produced a greater increase in the extracellular concentration of DA in hemidecorticate animals because more cytoplasmic DA was available for exchange-diffusion in hemidecorticate animals. Consistent with this idea, both amphetamine-stimulated DA release and the extracellular concentration of DOPAC returned to control levels by day 60 . It is not clear how hemidecortication might have produced a bilateral elevation in the cytoplasmic pool of DA. It may have been due to unknown nonspecific effects of the injury, or to loss of corticostriatal

\section{REFERENCES}

1 Alexander, G.E., Delong, M.R. and Strick, P.L., Parallel organization of functionally segregated circuits linking basal ganglia and cortex, Ann. Rev. Neurosci., 9 (1986) 357-381. projections that facilitate the release of DA. Evidence that corticostriatal glutamate projections synapse on or near DA terminals ${ }^{31}$, that electrical stimulation of motor cortex in the cat releases DA, and that application of glutamate to rat striatal slices releases $\mathrm{DA}^{15,30}$, suggests that changes in the cortical glutaminergic input could have been involved. The effect may have been bilateral because, even though most corticostriatal projections are ipsilateral, there are crossed corticostriatal projections ${ }^{46}$. In addition, it is known that hemidecortication can produce bilateral deficits in behavior. For example, Schallert and Whishaw ${ }^{41}$ described pronounced impairments in the response to tactile stimuli placed on the body of hemidecorticate rats, both ipsilateral and contralateral to the lesion, as well as the expected asymmetry. This bilateral depression in responsivity to tactile stimuli disappeared within a few days of surgery, a time course that parallels the changes in amphetamine-stimulated DA release and extracellular DOPAC seen in the present study.

In conclusion, the results of the present study indicate that hemidecortication produces only moderate changes in striatal DA neurotransmission, and these are very transient. Furthermore, there was no relationship between transient asymmetries in amphetamine-induced behavior produced by hemidecortication and asymmetries in striatal DA neurotransmission. The only clear change in striatal DA neurotransmission was bilateral, and consisted of a bilateral enhancement in amphetamine-stimulated DA release on the day following hemidecortication. A transient asymmetry in 5-HT metabolism did occur in association with transient behavioral asymmetries produced by hemidecortication, but this was not evident in vivo. It is concluded that although hemidecortication may produce transient changes in DA neurotransmission, these do not seem to be related to asymmetries in amphetamine-induced behavior produced by hemidecortication. They may be related, however, to the transient bilateral deficits in behavior produced by hemidecortication described previously ${ }^{41}$.

Acknowledgements. This research was supported by grants from MRC and the NCE to I.Q.W. and by Grant DA04294 to T.E.R. E.C. was supported by an Alberta Heritage Foundation Fellowship at the University of Lethbridge. The assistance of Scott D. Oddie is gratefully acknowledged.
2 Avemo, A., Antelman, S. and Ungerstedt, U., Rotational behavior after unilateral frontal cortex lesions in the rat, Acta Physiol. Scand., Suppl., 396 (1973) 77.

3 Boyeson, M.G. and Feeney, D.M., Striatal dopamine after cortical injury, Exp. Neurol., 89 (1985) 479-483. 
4 Bracha, S.H., Lyden, P.D. and Khansarinia, S., Delayed emergence of striatal dopaminergic hyperactivity after anterolateral ischemic cortical lesions in humans; evidence from turning behavior, Biol. Psychiat., 25 (1989) 265-274.

5 Castañeda, E., Whishaw, I.Q., Lermer, L. and Robinson, T.E., Dopamine depletion in neonatal rats: effects on behavior and striatal dopamine release assessed by intracerebral microdialysis during adulthood, Brain Research, 508 (1990) 30-39.

6 Castañeda, E., Whishaw, I.Q. and Robinson, T.E., Changes in striatal dopamine neurotransmission assessed with microdialysis following recovery from a bilateral 6-OHDA lesion: variation as a function of lesion size, $J$. Neurosci., 10 (1990) 1847-1854.

7 Clark, A.N.G. and Mankikar, G.D., D-Amphetamine in elderly patients refractory to rehabilitation procedures, J. Am. Geriatr. Soc., 27 (1979) 174-177.

8 Damsma, G., Boisvert, D.P., Mudrick, L.A., Wenkstern, D. and Fibiger, H.C., Effects of transient forebrain ischemia and pargyline on extracellular concentrations of dopamine, serotonin. and their metabolites in the rat striatum as determined by in vivo microdialysis, J. Neurochem., 54 (1990) 801-808.

9 DeLong, M.R., Motor functions of the basal ganglia: single-unit activity during movement. In F.O. Schmidt and F.G. Worden (Eds.), The Neurosciences: Third Study Program, MIT Press, Cambridge, MA, 1974, pp. 319-325.

10 Deuel, R.K. and Collins, R.C., Recovery from unilateral neglect, Exp. Neurol., 81 (1983) 733-748.

11 Donoghue, J.P. and Herkenham, M., Neostriatal projections from individual cortical fields conform to histochemically distinct striatal compartments in the rat, Brain Research, 365 (1986) $397-403$

12 Feeney, D.M., Sutton, R.L., Boyeson, M.G., Hovda, D.A and Dail, W.G., The locus coeruleus and cerebral metabolism: recovery of function after cortical injury, Physiol. Psych., 13 (1985) 197-203.

13 Fisher, J.F. and Cho, A.K., Chemical release of dopamine from striatal homogenates: evidence for an exchange diffusion model, J. Pharmacol. Exp. Ther., 208 (1979) 203-209.

14 Gilman, S., Dauth, G.W., Frey, K.A. and Penney, J.B., Experimental hemiplegia in the monkey: basal ganglia glucose activity during recovery, Ann. Neurol., 22 (1987) 370-376.

15 Giorguieff, M.F., Kemel, M.L. and Glowinski, J., Presynaptic effect of L-glutamic acid on dopamine release in striatal slices, Neurosci. Lett., 6 (1977) 77-78.

16 Glick, S.D. and Greenstein, S., Possible modulating influence of frontal cortex on nigro-striatal function, $\mathrm{Br}$. J. Pharmacol., 49 (1973) 316-321.

17 Gordon, K., Statman, D., Jonhston, M.V., Robinson, T.E. Becker, J.B. and Silverstein, F.S., Transient hypoxia alters striatal catecholamine metabolism in immature brain: an in vivo microdialysis study, $J$. Neurochem., 54 (1990) 605-611.

18 Graybiel, A.M., Neurochemically specified subsystems in the basal ganglia: Ciba Foundation Symposium No. 107. In D Evered and M. O'Connor (Eds.), Functions of the Basal Ganglia, Pittman, London, 1984, pp. 114-144.

19 Greenstein, S. and Glick, S.D., Improved automated apparatus for recording rotation (circling behavior) in rats and mice, Pharmacol. Biochem. Behav., 3 (1975) 507-510.

20 Heffner, T.G., Hartman, J.A. and Seiden, L.S., A rapid method for the regional dissection of the rat brain, Pharmacol. Biochem. Behav., 13 (1980) 453-456.

21 Itoh, S., Hssiao, S. and Katsuura, G., Dopaminergic behavior in frontal decorticate rats, Physiol. Behav., 35 (1985) 109-112.

22 Jerussi, T.P. and Glick, S.D., Amphetamine-induced rotation in rats without lesions, Neuropharmacology, 13 (1974) 283-286.

23 Kennard, M.A. and Ectors, L., Forced circling in monkeys following lesions of the frontal lobes, J. Neurophysiol., 1 (1938) 45-54.

24 Kuczenski, R., Biochemical action of amphetamine and other stimulants. In I. Creese, (Ed.), Stimulants: Neurochemical, Behavioral and Clinical Perspectives, Raven, New York, 1983, pp.
$31-61$

25 Kuczenski, R. and Segal, D., Concomitant characterization of behavioral and striatal neurotransmitter response to amphetamine using in vivo microdialysis, J. Neurosci., 9 (1989) 2051 2065 .

26 Monakow, C.V. von, Lokalization der Hirnfunktionen, $J$. Psy chol. Neurol., 17 (1911) 185-200. Reprinted in G. von Bonin, The Cerebral Cortex, C. Thomas, Springfield, IL, 1960.

27 Paxinos, G. and Watson, C., The Rat Brain in Stereotaxic Coordinates, 2nd edn., Academic, New York. 1986.

28 Pisa, M., Motor functions of the striatum in the rat: critical role of the lateral region in tongue and forelimb reaching, Neuroscience, 24 (1988) 453-463.

29 Pycock, C.J., Commentary: turning behaviour in animals, Neuroscience, 5 (1980) 461-514.

30 Roberts, P.J. and Anderson, S.D., Stimulatory effect of L-glutamate and related amino acids of ${ }^{3} \mathrm{D}$-dopamine from rat striatum: an in vitro model for glutamate actins, J. Neurochem., 32 (1979) 1539-1545.

31 Roberts, P.J., McBean, G.J., Sharif, N.A. and Thomas, E.M. Striatal glutamatergic function: modification following specific lesions, Brain Research, 235 (1982) 83-90.

32 Robertson, H.A., Cerebral decortication reverses the effect of amphetamine on striatal $\mathrm{D}_{2}$ dopamine binding site density, Neurosci. Lett., 72 (1986) 325-329.

33 Robinson, R.G. and Coyle, J.T., Lateralization of catecholaminergic and behavioral response to cerebral infarction in the rat, Life Sci., 24 (1979) 943-950.

34 Robinson, R.G. and Coyle, J.T., The differential effect of right versus left hemispheric cerebral infarction on catecholamines and behavior in the rat, Brain Research, 188 (1980) 63-78.

35 Robinson, T.E., Behavioral sensitization: characterization of enduring changes in rotational behavior produced by intermittent injections of amphetamine in male and female rats, Psy. chopharmacology, 84 (1984) 466-475.

36 Robinson, T.E. and Camp, D.M., The feasibility of repeated microdialysis for within-subjects design experiments: studies on the mesostriatal dopamine system. In T.E. Robinson and J.B Justice, Jr. (Eds.), Microdialysis in the Neurosciences, Elsevier. Amsterdam, 1991

37 Robinson, T.E., Becker, J.B., Young, E.A., Akil, H. and Castañeda, E., The effects of footshock stress on regional brain dopamine metabolism and pituitary $\beta$-endorphin release in rats previously sensitized to amphetamine, Neuropharmacology, 26 (1987) 679-691

38 Robinson, T.E., Jurson, P.A., Bennett, J.A. and Bentgen, K.M., Persistent sensitization of dopamine neurotransmission in ventral striatum (nucleus accumbens) produced by past experience with $(+)$-amphetamine: a dialysis study in freely moving rat, Brain Research, 462 (1988) 211-222.

39 Robinson, T.E. and Whishaw, I.Q., Normalization of extracellular dopamine in striatum following recovery from a partial unilateral 6-OHDA lesion of the substantia nigra: a microdialysis study in freely moving rat, Brain Research, 450 (1988) 209224.

40 Scatton, B., Worms, P., Lloyd, K.G. and Bartholini, G., Cortical modulation of striatal function, Brain Research, 232 (1982) 331-343.

41 Schallert, T. and Whishaw, I.Q., Bilateral cutaneous stimulation of the somatosensory system in hemidecorticate rats, $B e$ hav. Neurosci., 98 (1984) 518-540.

42 Sherrington, C.S., The integrative action of the nervous system. Yale University Press, New Haven, CT, 1906.

43 Whishaw, I.Q. and Kolb, B., 'Stick out your tongue': tongue protrusion in neocortex and hypothalamic damaged rats, Physiol. Behav., 30 (1983) 471-480.

44 Whishaw, I.Q., Schallert, T. and Kolb, B., An analysis of feeding and sensorimotor abilities of rats after decortication, $J$. Comp. Physiol. Psych., 95 (1981) 85-103.

45 Whishaw, I.Q., Sutheriand R.J., Kolb, B. and Becker, J.B., 
Effects of neonatal forebrain noradrenaline depletion on recovery from brain damage: performance on a spatial navigation task as a function of age of surgery and postsurgical housing, Behav. Neural Biol., 46 (1986) 285-307.

46 Wilson, C.J., Morphology and synaptic connections of crossed corticostriatal neurons in the rat, J. Comp. Neurol., 263 (1987) 567-580.
47 Yamamoto, B.K. and Pehek, E.A., A neurochemical heterogeneity of the rat striatum as measured by in vivo electrochemistry and microdialysis, Brain Research, 506 (1990) 236-242.

48 Zetterström, T., Sharp, T. and Ungerstedt, U., Further evaluation of the mechanism by which amphetamine reduces striatal dopamine metabolism: a brain dialysis study, Eur. J. Pharmacol., 132 (1986) 1-9. 